\title{
Sustainability of new work practises and building concepts
}

\author{
Prof.Dr.Niklaus Kohler \\ Institut für Industrielle Bauproduktion - ifib Universität Karlsruhe \\ Englerstrasse 7, D-75128 Karlsruhe \\ email : niklaus@ifib.uni-karlsruhe.de
}

\begin{abstract}
New forms of communication and co-operation do not have the same environmental impact pattern as current forms of work. Environmental impacts are produced by work technologies (mainly communication technologies), buildings (construction, maintenance, operation and destruction) and transport (induced by work relations and housing). The thesis that new information technologies reduce transport and building energy consumption has not been verified in practice until now. The contribution discusses the interrelation between different impacts, gives quantitative data of environmental impact based on the combination of existing life cycle analysis and tries to estimate possible future developments. The question of the necessity of new buildings and the possible development of virtual buildings is discussed in relation with sustainable development.
\end{abstract}

keywords : buildings, work practise, life cycle assessement, sustainability

\section{Introduction :}

New work practices like telework, new technologies like Internet, new forms of buildings like ,intelligent“ or „cooperative“ buildings are presented as having large advantages from an environmental point of view by inducing less motorised traffic, smaller energy consumption, and the use of less resources through the dematerialisation of their components. These advantages are often summed up as part of a ,sustainable“ development. The contribution will start out by giving a working definition of the different aspects of sustainability and life cycle assessment (LCA). The possibility of life cycle assessment of new work practises, communication technologies and buildings are discussed; existing quantitative attempts are situated. The necessity of new building types for new work practises is analysed and different building concepts are discussed. The contribution tries finally to answer the question on how new work practices and new technologies influence operation and management of individual buildings and the building stock in a long term perspective. 


\section{Definition of Sustainability}

The German parliamentary Enquete-Commission for the „Schutz des Menschen und der Umwelt" gives the following definition of sustainable management : , The rate of decrease of renewable resources should not be larger than their rate of regeneration. Non renewable resources should only be used to the extent that an equivalent replacement in form of new renewable resources or a higher efficiency of both renewable and non renewable resources can be granted. The environmental impact through emissions and waste should be adapted to the reception capacity of the environmental compartments.“ [ENQ97]. In general a sustainable development should assure social, economical and environmental (ecological) benefits.

\section{Assessment of Sustainability}

There are different methods to assess the three aspects of sustainable development, in general within the framework of a technology assessment. There are very few attempts to an overall assessment of new communication technologies because of their complexity and their multiple material interrelations. We will concentrate in this contribution on the assessment of the environmental or ecological sustainability. The most common assessment method is Life Cycle Assessment (LCA). In order to determine the interaction between a product, a service or a technology and the environment [ODU83], it is necessary to understand their environmental aspects, generally through the mass and energy flows induced throughout the product life cycle. According to [SET93], [HEI92] there are 4 steps in an LCA.

- Objectives: system limits and functional units

- Inventory: mass input and output, including upstream and downstream process

- Classification: association of inputs (causes) with effects on the environment

- Evaluation: overall evaluation by aggregation of different effects

The establishment of consistent system limits is a first problem. Inside the modular approach which has been developed in the LCA community there is a possibility to link a specific domain of LCA to upstream and downstream process chains through common system limits. This method works well in the field of energy, transport, material and consumers products as well as buildings. It is however difficult to determine the system limits of complex systems like the communication systems. Another difficult problem when applying LCA to complex situations, is the definition of a common reference, a functional unit. Mass flows, impacts and effects can be related to a person, a workplace, a work unit, a technological unit, a building unit etc. Conventional office work can be described by a work hour of a person at a certain site using a certain technology. In the case of telework there are two or even more work sites, several types of equipment and the transport between the workplaces has to be taken into account in terms of time and distance. For each phase there has to be a specific LCA. 


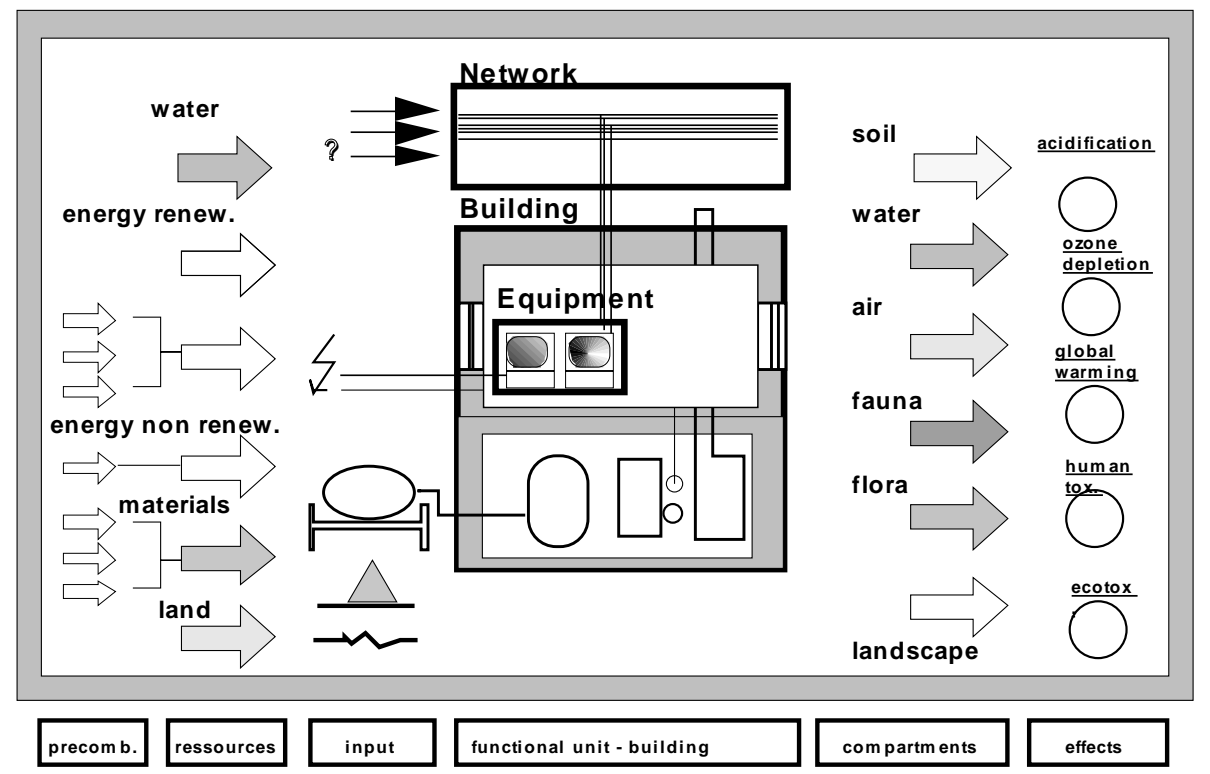

Fig. 1 : System limits [KOH98] in an LCA of buildings and new communication technologies

\section{Assessment of work practices, communication technologies and buildings}

\section{1 form of work}

Current office work is considered as the reference, with one workplace linked to a network which is outside the system limits. The case of telework has been studied by [ÖKO97]. The results show that the difference in primary energy consumption per work place depends essentially on the resulting amount of individual transport. For the analysed real case the balance was negative for telework, in an optimised solution with little individual transportation, optimal use of equipment and energy efficient hardware the telework had a slightly positive balance.

Distributed work practices and virtual enterprises allow to improve the communication within a team and to overcome the loss of time due to individual transport through synchronic and asynchronic collaboration over networks. The economic savings of teleconferences are quite evident and the reduction of the environmental impacts should be even larger than the economic savings (actual transportation costs do not take sufficiently into account environmental impacts). However there are no overall studies of the effects of distributed work practice. The resulting raise in productivity reduce the number of work places. The unemployed 
persons are no more inside the system limits, they continue however to create environmental impacts through other activities.

4.2 information and communication technologies :

There are two parts which are strongly linked but which cannot be analysed in the same way. The communication networks are very difficult to analyse as process chains because of their complexity and because of the fact that the same network is often used for different types of existing and future applications. In some cases it is possible to estimate the environmental impact of complex systems through a macroeconomic input/output analysis coupled to emission coefficients and resource consumption. The German macroeconomic input-output matrix [ITA97] is not detailed enough to isolate the economic activities for the production, repair and operation of large communication networks. Furthermore there are large international interdependencies.

Personal computers and other distributed input/output devices have been analysed and there are several LCA for personal computers.[GRO94],[MCC93],[SOL95] . The main findings are :

- the production of the hardware has larger impacts than its operation

- the mass input is much higher than the mass of the components

- the waste is composed of a large number of often not identified materials

- the screens based on cathodic tube technology have large production and operation energy needs.

\subsection{Building construction and operation :}

Building LCA is certainly the most well developed. [KOH94],[KOH95],[KOH98]. The environmental assessment is realised by a modular combination of upstream and downstream process analyses. All energy and mass flows are are derived from usual quantity surveying and building construction process data. The main problem lies in the assumptions concerning the very long life cycle. Basic data on all types of industrial process can be found in [FRI95],[GEM95].

Most effect oriented environmental impact factors show a relation (impacts through building and refurbishment versus impacts through operation) over an assumed life time of 80 to 100 years of approx. 1:6 for buildings with low energy efficiency up to 1:1 for buildings with very high energy efficiency. The relation is somewhat different for human toxic and ecotoxic indicators where the impacts through building and refurbishment are more import. The situation of a building in relation to public transport, the distance to the the centre and to residences, and the type of transport used can make a large difference in environmental impacts.

As an illustration the overall (primary) energy consumption for different combinations of building types, work equipment and amount of generated transport has been estimated. The basic data from [IFIB95] [KOH94] [KOH98] have been used. Even if a large database has been used for the basic process, the results are partial and the accuracy can be estimated at $+/-20 \%$. The primary energy has been chosen as an 
indicator for environmental impact because of the availability of data for all the considered process. It is however not the only indicator, it correlates rather well with global warming effects but rather badly with acidification and not at all with environmental or human toxicity.

Certain assumptions have been made about the type of buildings. The so called highly equipped buildings correspond to buildings with moveable partitions suspended ceilings and floors and generalised HVAC equipment. The operation energy needs (heat and electricity) even for efficient ventilation, heating, cooling and lighting equipment are very high. The construction, refurbishment and maintenance energy parts are high because of the particular materials and components used in this type of building. Transport plays a very important part in all solutions with large part of individual transportation. For the work equipment the data from LCA for PCs been adapted. The number of years of use of the equipment is quite important. Through upgrading the equipment can be used much longer. Good design allows a high degree of reutilisation on a high level at the end of the life time for all components. This effect has not been taken into account in the calculation.

\begin{tabular}{|c|c|c|c|c|c|c|c|c|}
\hline \multicolumn{9}{|c|}{ Building characteristics } \\
\hline \multirow[t]{2}{*}{ Building type } & highly & highly & highly & highly & aver. & aver. & best & exist. \\
\hline & equip. & equip. & equip. & equip. & equip. & equip. & techn. & \\
\hline Building state & new & new & new & new & new & new & new & refurb. \\
\hline Build.energ.efficienc. & low & aver. & high & low & high & high & very $\mathrm{h}$ & high \\
\hline Work equip. efficien. & low & low & aver. & low & high & high & very $\mathrm{h}$ & very $\mathrm{h}$ \\
\hline \multicolumn{9}{|l|}{ Use characteristics } \\
\hline Surface p.person [m2] & 20 & 20 & 20 & 20 & 20 & 20 & 20 & 20 \\
\hline Building life time [y] & 30 & 100 & 100 & 30 & 100 & 100 & 100 & 100 \\
\hline Refurbishment [-] & & 2 & 2 & & 2 & 2 & 2 & 2 \\
\hline Equipm.life time [y] & 3 & 3 & 5 & 3 & 6 & 6 & 8 & 8 \\
\hline Transp. distance $[\mathrm{km}]$ & 50 & 50 & 30 & 10 & 30 & 10 & 10 & 10 \\
\hline Public transport [\%] & 10 & 10 & 10 & 70 & 10 & 70 & 70 & 90 \\
\hline \multicolumn{9}{|c|}{ Primary energy consumption $[\mathrm{kWh}]$ per work place $(20 \mathrm{~m} 2)$ per year } \\
\hline Build.construction & 3467 & 2800 & 2800 & 3667 & 1640 & 1640 & 1380 & 960 \\
\hline Building operation & 10760 & 6596 & 4606 & 10760 & 4606 & 4606 & 2432 & 3298 \\
\hline IT equip.\&operation & 3050 & 3050 & 1490 & 3050 & 1157 & 1157 & 725 & 725 \\
\hline Transport & 13233 & 13233 & 7940 & 1359 & 7940 & 1359 & 1359 & 930 \\
\hline Total $[\mathrm{kWh} / \mathrm{y}]$ & 30509 & 25679 & 16836 & 18836 & 15342 & 8762 & 5896 & 5913 \\
\hline Relation [\%] & 100 & 84 & 55 & 62 & 50 & 29 & 19 & 19 \\
\hline
\end{tabular}

Fig. 2 : Primary energy consumption for different solutions 
As an alternative to highly equipped buildings, very simple buildings with sophisticated energy conservation and passive solar design, little technical building equipment and long lasting, low impact materials have been analysed. They are to be compared to the case of very efficient refurbishment. In all these cases the ,intelligence " lies in the design and operation process and not in the control equipment. If they are well designed the adaptability of such buildings to new work practises and new communication technologies is equivalent to the highly equipped buildings.

\section{What kind of buildings do we need for new work practises and new communication techniques?}

The statement that ,current work spaces are not prepared for nor oriented towards the integration of IT infrastructure supporting work processes with the infrastructure for managing and operating buildings" should be discussed. If in the beginning of the computer application 20 years ago, computers needed very particular climatic conditions and developed large amounts of process heat, needing special airconditioned rooms, this is not true any more for current IT and will be even less true for the coming applications. It means that there is no need for complicated HVAC equipment if buildings are designed with the available design tools and run in a efficient manner (at least in central Europe). The space for networks has also been dramatically reduced, new developments allow to transport more and more information through TV cable and even through the electrical current distribution. As to the spatial capacity all buildings with sufficient ceiling heights and which are not too deep, can be adapted and equipped with all kind of electronic input/output devices. This is particularly true for older industrial and warehouse type buildings. The refurbishment of large parts of the recent office buildings will allow to correct at least some of the design and construction errors and equip these buildings with new networks. The development of always smaller, more decentralised and more autonomous IT allows new forms of work and of communication to adapt to a large portion of existing buildings. The argument that existing buildings are not capable of receiving IT infrastructure and new work practise and that there is therefore a need for new buildings, is probably no longer correct.

\section{Buildings in a long term perspective :}

The studies of the evolution of the German [ENQ96] and probably most other European buildings stocks show the following tendencies: - new building activities , above all of office buildings are continually decreasing - there are many old empty buildings (industry and warehouses) 
- there is growing amount of empty new highly equipped office buildings resulting from building overproduction and effects of company reengineering (downsizing, outsourcing etc.)

- there is a problem of financial allocation between new construction, refurbishment and maintenance

- the mass flows (input) induced by building activities are 4 to 10 times higher than the waste mass flows (output). There is growing concern over the use of resources (materials, energy, land) and the resulting environmental impacts

- there is a growing risk of contamination of the whole building stock by undesired materials.

- there is a growing awareness of the risks of poor indoor environment quality (building illness through bad HVAC equipment, emissions from building materials, electrosmog from electronic equipment etc.)

The simulation of the evolution of building activities, mass flows, energy flows, land use and emissions show the that a sustainable development of the building stock needs a dramatic reduction in the operation energy, the replacement of new building and material production through longer use and recycling at a high level of buildings and components. The reduction of special waste (which includes electronic waste) through better design of buildings and equipment is also a more general issue.

At the same time the demand for surfaces for service activities and for innovative small industrial, service and R\&D firms shows the following tendencies :

- rapid availability of space with good IT connections,

- possibility to leave or increase surface in short intervals

- low rent and operation costs

- possibility to install rapidly IT technologies

- rent instead of building or buying (new construction is too slow, too rigid, too expensive, too capital intensive)

These demands are more and more taken into account by firms specialised in rapid refurbishment and transformation of existing, often empty buildings. As new owners these firms have a specific interest in managing the buildings in a flexible long term perspective. They develop their own adapted and efficient FM tools independent of the actual user. Large firms have a tendency to sell their own building stock.

A similar development can be observed in the tendency towards leasing of office equipment (photocopy machines etc.). One of the largest firms in this field continues to use the main components of machines and replaces only the obsolete parts. This strategy is economically and ecologically justified.

The overall strategy of sustainable development in the built environment, taking into account economic, social and ecological aspects is based on the following hierarchy :

- maintain and improve the existing urban and regional environment

- manage the building stock as the largest financial, physical and cultural capital of industrial societies in a long term perspective. This means that the stock becomes the basic resource [HAS95].

- develop techniques to maintain, refurbish and adapt the existing buildings to new requirements. Adapt new techniques to fit the existing buildings 
- for new buildings (replacement of demolished buildings) create long term adaptable structures.

It has proved that short term adaptations of buildings to rapidly changing technical and social needs are inefficient in a long term perspective. There is a clear strategic difference between the short time management of buildings (use) and the long term (intergeneration) management of building stocks and urban contexts. The architectural efforts should therefore be concentrated on the imagination of a new social and cultural spatial environment which would accompany and improve new forms of work and communication instead of trying to adapt objects with life times of decades to IT techniques which change every three years.

\section{Real buildings and virtual buildings}

The most promising aspect of the discussion about new work practises and new communication techniques resides certainly in the development of new conceptual tools like virtual worlds, virtual buildings, information building etc. There should be no confusion between the long term management of the real physical environment and the management of virtual worlds. Most attempts to qualify and differentiate buildings in a special way (like ,intelligent" buildings) neglect the extremely complex nature of real buildings which can not separated from their cultural and historic significance. Buildings in this sense are non renewable resources. Simplistic technical concepts might in their restrictive way even lead to technically wrong conclusions, because they underestimate the extremely rapid development of IT. The potential of new simulation methods to improve the energy and environmental design methods as well as the long term management of building stocks will probably play an important role.

The integration of new work concepts and communication technologies on one side and building design and management on the other side lies probably in the use of the building metaphor in many IT applications. Research in this field could improve considerably the domination of complexity arising from the modelling of large production and communication processes. The use of buildings in virtual worlds could coexist very well with the long term ,sustainable“ use of real buildings as a complex social and cultural environment. There is no need to adapt existing buildings to virtual worlds. 


\section{References :}

[ENQ97]Enquete Kommission „Schutz des Menschen und der Umwelt“ des Deutschen Bundestages : Konzept Nachhaltigkeit. Deutscher Bundestag 1997

[EQK96]ITAS,IFIB,IWU, Uni.Dortmund,Fachhochschule Kiel : Stoffströme und Kosten im Bereich Bauen und Wohnen. Studie im Auftrag der Enquete Kommission zum Schutz von Mensch und Umwelt des deutschen Bundestages. Karlsruhe. 1996.

[FRI95]FRISCHKNECHT, R et al: ÖKOINVENTARE für Energiesysteme. ETHZ/ESU.Bern 1995.

[GEM95]FRITSCHE,U; RAUSCH,L;SIMON, K.-H:Öko-Institut/Gesamthochschule Kassel 1989: Umweltwirkungsanalyse für Energiesysteme: Gesamt-Emissions-Modell Integrierter Systeme (GEMIS), Darmstadt/Kassel 1997

[GRO94]GROTE, A : Grüne Rechnung. Das Produkt Computer in der Ökobilanz. c't 12 /1994/p.92

[HAS95]Hassler, U.[edit] Das Denkmal als Altlast? Auf dem Weg in die Reparaturgesellschaft? Universität Dortmund 1995. ICOMOS Publication Heft XXI, 1996 [HEI92]HEIJUNGS, R. et al (1992): "Environmental life cycle assessment of products; Guide and Backgrounds "; National Reuse of Waste Research Programme , CML, Leiden [IFIB95]IFIB-HAB Weimar-ETHZ ESU: Ökoinventare von Baustoffen. Karlsruhe -1995 [ITA97]. ITAS - Institut für Technikfolgenabschätzung:Input-Outputanalyse und Emitentenstruktur. In TA Nachrichten 3/4/. Nov. 1997, p.117

[KOH94]KOHLER N et al : Energie und Stoffbilanzen von Gebäuden während ihrer Lebensdauer.Schlussbericht Forschungsprojekt BEW. Ifib - Universität Karlsruhe 1994 [KOH95]KOHLER, N. Life cycle models of buildings. In EuropIA'95. 5th. Intern. Conference on the Application of Artificial Intelligence to Architecture and Civil Engineering. Hermes, Paris 1995

[KOH98] KOHLER, N: Lebenszyklusbezogene Bewertung von Gebäuden - Methoden und Vergleiche. DAM Deutsches Architekturmuseum. Frankfurt, 1998 (to be published)

[KUB95] KUBICEK,H; MÜLLER,G; NEUMANN, K-H; RAUBOLDE,E ; ROSSNAGEL, A : Jahrbuch „Telekommunikation und Gesellschaft 1995 und 1997“, Heidelberg 1995-1997

[MCC93] Microelectronics and Computer Technology Corporation (MCC) Environmental Consciousness: A strategic Competitiveness Issue for the Electronics and Computer Industry. 1993

[ODUH83] ODUM H.T.: System Ecology, New York,1983

[ÖKO97] ÖKOINSTITUT E.V. : Umweltschutz im Cyberspace. Zur Rolle der Telekommunikation für eine nachhaltige Entwicklung. Freiburg 1997

[SET93]CONSOLI, J. et al. Guidelines for Life Cycle Assessment: A Code of Practice. SETAC-Europe Bruxelles, 1993.

[SOL95]SOLDERA, M: Öko-Computer. Vergleich eines Öko PC mit einem herkömmlichen $P C$ anhand einer Lebenszyklusbilanz. Gebensdorf $(\mathrm{CH}) 1995$ 